\title{
Nanostructured Lipid Carrier: A Potential System for Enhanced Oral Bioavailability of Felodipine
}

\author{
Archana Sidagouda Patil ${ }^{\star}$, Vinayak Jaknoor, Anand Panchakshari Gadad, \\ Rajashree Shashidhar Masareddy, Panchaxari Mallappa Danadagi, Udaykumar Bolmal
}

Department of Pharmaceutics, KLES College of Pharmacy, Belagavi, KLE Academy of Higher Education and Research, Belagavi, Karnataka, INDIA.

\begin{abstract}
Background: Felodipine is BCS class II drug with poor and variable bioavailability due to its insolubility in water $(19 \mathrm{mg} / \mathrm{L})$ and extensive metabolism in liver and gut. Thus, in the study Nanostructured lipid carriers (NLCs) of Felodipine were formulated to improve its solubility and bioavailability. Methods: NLCs loaded with Felodipine were prepared by high shear homogenization with ultrasonication. The NLCs were characterized for particle size, polydispersity index, entrapment efficiency, content of drug, in vitro drug release studies, stability studies and in vivo bioavailability studies. Results: The mean particle size and polydispersity index for optimized formulation F2 was found to be $187.0 \pm 0.06$ and $0.259 \pm 0.002$ respectively. The drug content achieved was between the ranges of $51.15 \pm 0.01$ to $69.14 \pm 003 \%$ for $F 1$ to F5 formulations. The zeta potential of optimized formulation was found to be $-38.2 \mathrm{mV}$, which showed good stability. Formulation F2 showed highest percentage entrapment efficiency of $75.15 \pm 0.003$. In vitro drug release studies showed sustained release pattern with maximum drug release of $72.82 \%$ by $\mathrm{F} 2$ formulation at the end of $12 \mathrm{~h}$. The bioavailability studies demonstrated significant enhancement in bioavailability of Felodipine NLCs in comparison to marketed product. Stability studies carried out for optimized formulation F2 showed that the NLCs are more stable at $4 \pm 2{ }^{\circ} \mathrm{C}$. Conclusion: Nanostructured lipid carriers loaded with Felodipine were able enhance the bioavailability of drug by 2.0 folds in comparison to marketed product and also demonstrated sustained drug release pattern for longer period of time.
\end{abstract}

Key words: Felodipine, Oleic acid, Compritol ATO 888, High shear homogenizer, Oral bioavailability.

\section{INTRODUCTION}

Hypertension is defined as a systolic blood pressure $\geq 140 \mathrm{mmHg}$ and/or a diastolic pressure $\geq 90 \mathrm{mmHg}$, is one of the most common chronic disease. ${ }^{1}$ Calcium channel blockers are primarily utilised for the therapy of systemic arterial hypertension. A dihydropyridine calcium channel blocker Felodipine, has been extensively used in the treatment of hypertension. ${ }^{2}$ Felodipine is BCS class II drug and is practically insoluble in water $(19 \mathrm{mg} / \mathrm{L})$. It is extensively metabolized in liver and gut as well as entirely excreted as metabolites. Felodipine has poor and variable bioavailability (15-20\%). ${ }^{3}$ Various studies were conducted by researchers to increase the solubility and oral bioavailability of Felodipine. For instance, Dong HW et al., prepared solid dispersions(SD)ofFelodipinebysupercritical anti-solvent precipitation method which showed higher dissolution rate of drug over $90 \%$ in 2 h. $^{4}$ Cong L et al., prepared nanocrystals of Felodipine resulting in an increased dissolution rate with $\mathrm{AUC}_{0}-\mathrm{t}$ value of 1.6-fold higher than that of the commercial tablets. ${ }^{5}$ Sahu et al., prepared and evaluated Felodipine nanosuspensions showing up to $79.67 \%$ release in $4 \mathrm{~h}^{6}{ }^{6}$ Grandhi $S$ et al., formulated matrix tablet from solid dispersions of Felodipine
Submission Date: 14-12-2020; Revision Date: 06-04-2021; Accepted Date: 28-07-2021.

DOI: 10.5530/ijper.56.1.10 Correspondence: Dr. Archana S Patil, Assistant Professor, Department of Pharmaceutics, KLES College of Pharmacy, Belagavi, KLE Academy of Higher Education and Research, Belagavi-590010, Karnataka, INDIA.

E-mail: archupharma@gmail. com

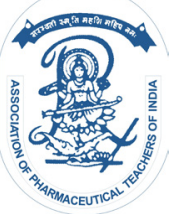

www.ijper.org 
by wet granulation technique. These tablets showed extended drug release of $87.84 \%$ in $8 \mathrm{~h}^{7}$ Anusha A, developed self micro emulsifying drug delivery system (SMEDDS) of Felodipine, where the dissolution from liquid SMEDDS and solid SMEDDS was significantly high $(P<0.0001)$ compared to drug suspension. ${ }^{8}$ Many solid dispersions of Felodipine with varying polymers or methods of preparations were also tried to increase the solubility of drug.

Pharmaceutical nanotechnology has taken the advantage of the advent of nanotechnology; new pharmaceutical dosage forms are under development to deliver many pharmaceutical drug molecules. ${ }^{9}$ Poor intrinsic dissolution rate and aqueous solubility of drug greatly influence the oral drug delivery. Recently, NLCs have been widely attracting researchers for the oral delivery of lipophilic drugs. ${ }^{10}$ NLCs with unique characteristics can be formulated by combining solid and liquid lipids which provide firm loading of drug molecule inside the matrix during the shelf life. ${ }^{11}$ Solubility of drug is higher in liquid lipid as compared solid lipid. Due to this, NLCs can achieve high drug loading and slow drug release thereby, avoids drug loss prior to the solid lipid decomposition. ${ }^{12}$ By review of literature, it was understood that high shear homogenization is the simple, rapid and easy method to prepare NLCs. Thus, the present study attempts to design and evaluate Nanostructured lipid carrier of Felodipine with an aim to enhance its solubility and oral bioavailability.

\section{MATERIALS AND METHODS}

\section{Materials}

Felodipine pure drug was obtained as a free gift sample from Cipla Pvt. Ltd. Bangalore, India. Compritol ATO 888 was obtained by Gattefosse, France. Oleic acid was purchased from S.D Fine Chemicals, Mumbai, India. Poloxamer 188 was purchased from Ozone International, Mumbai, India. Dialysis membrane with molecular weight cut off of 12000-14000 Dalton was purchased from Hi Media Laboratories Pvt. Ltd. Mumbai, India. All the other chemicals used were of analytical grade.

\section{Methods}

\section{Preliminary Lipid Screening}

Selection of the suitable lipids to develop lipid nanoparticles is one of the crucial parameter. Thus, Felodipine solubility was determined in various solid and liquid lipids, to select the suitable lipid to encapsulate the large quantity of drug. Lipid screening was done by dissolving drug with increasing quantity in different melted solid lipids (Approximately 100mg) and determined the maximum amount of drug dissolved in every lipid.

\section{Optimization of Process Parameters}

For process optimization, homogenization speed, homogenization time, ultrasonication time and surfactant concentrations were varied (Table 1) and evaluated for particle size and size distribution.

\section{Preparation of NLCs by High Shear Homogenization Followed by Ultrasonication Method}

NLCs were prepared by high shear homogenisation and ultrasonication method..$^{13}$ In the method, lipids were melted $\left(10{ }^{\circ} \mathrm{C}\right.$ above their melting point) and to the melted mass drug was added slowly. The dispersion was kept at the same temperature until it becomes optically clear. The aqueous phase of surfactant solution was prepared separately by dissolving Poloxamer 188 with distilled water and heated to the same temperature as that of lipid solution. Hot solution of surfactant was added in to the lipid phase dropwise with continuous stirring on magnetic stirrer for $10 \mathrm{~min}$. The mixing was further continued with high shear homogenizer at $12000 \mathrm{rpm}$ for about $30 \mathrm{~min}$ following ultrasonication for $15 \mathrm{~min}$. The prepared formulation was then stored at $4^{\circ} \mathrm{C}$. The composition of NLCs formulations F1 to F5 is given in Table 2 as well as the method is depicted with schematic representation in Figure 1.

\section{Evaluation of Felodipine NLCs Formulations}

Determination of Particle Size, PDI and Zeta Potential

The size distribution of the formulations was measured by Dynamic Light Scattering Particle Size Analyzer (Nanotrac Particle Size Analyzer). The zeta potential

\begin{tabular}{|c|c|c|c|c|c|}
\hline 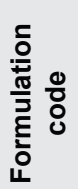 & 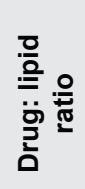 & 옴 & 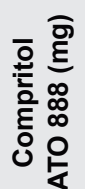 & $\begin{array}{l}\frac{\overline{0}}{0} \\
\frac{0}{\pi} \\
\frac{0}{\sigma} \\
\frac{0}{0}\end{array}$ & 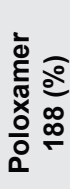 \\
\hline F1 & $1: 1$ & 10 & 10 & 10 & 1.0 \\
\hline F2 & $1: 1.5$ & 10 & 15 & 15 & 1.0 \\
\hline F3 & $1: 2$ & 10 & 20 & 20 & 1.0 \\
\hline F4 & $1: 2.5$ & 10 & 25 & 25 & 1.0 \\
\hline F5 & $1: 3$ & 10 & 30 & 30 & 1.0 \\
\hline
\end{tabular}

Drug: Felodipine, Solid lipid: Compritol ATO 888, liquid lipid: Oleic acid, surfactant: Poloxamer 188 


\begin{tabular}{|c|c|c|c|}
\hline \multirow{3}{*}{$\begin{array}{l}\text { Homogenization speed } \\
\qquad(\mathrm{rpm})\end{array}$} & $\begin{array}{c}\text { Speed } \\
9000\end{array}$ & $\begin{array}{c}\text { Particle size } \\
968.25\end{array}$ & $\begin{array}{l}\text { PDI } \\
1.95\end{array}$ \\
\hline & 12000 & 729.36 & 1.25 \\
\hline & 14000 & 310.18 & 0.43 \\
\hline \multirow{3}{*}{$\begin{array}{l}\text { Homogenization time } \\
\text { (mins) }\end{array}$} & 10 & 754.63 & 0.48 \\
\hline & 20 & 567.27 & 0.36 \\
\hline & 30 & 420.32 & 0.28 \\
\hline \multirow{3}{*}{$\begin{array}{l}\text { Ultrasonication time } \\
\text { (mins) }\end{array}$} & 5 & 432.4 & 0.46 \\
\hline & 10 & 329.8 & 0.32 \\
\hline & 15 & 221.4 & 0.21 \\
\hline \multirow{4}{*}{$\begin{array}{l}\text { Surfactant concentration } \\
\qquad(\% \mathrm{w} / \mathrm{v})\end{array}$} & 0.5 & 233.5 & 0.94 \\
\hline & 1 & 229.6 & 0.41 \\
\hline & 1.5 & 342.2 & 0.89 \\
\hline & 2 & 386.7 & 0.97 \\
\hline
\end{tabular}

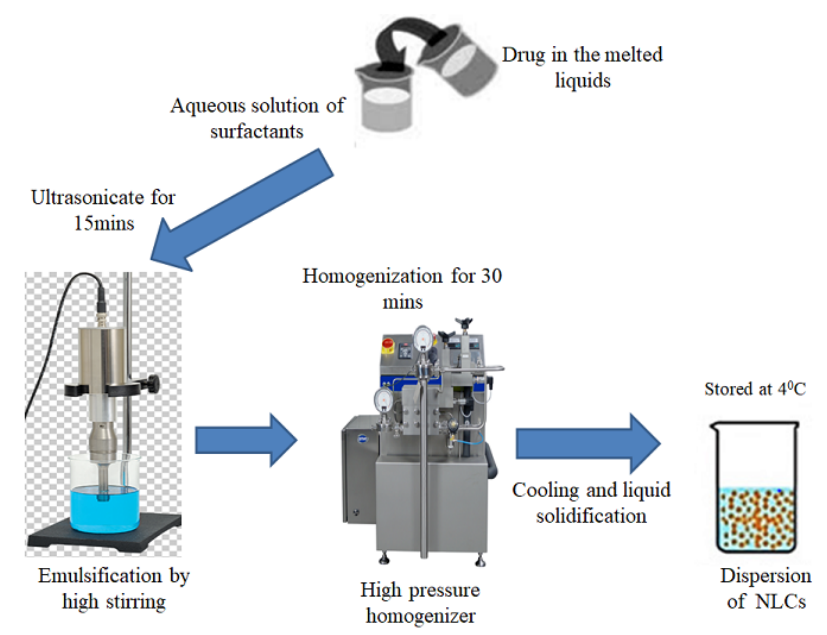

Figure 1: Representation of NLC's preparation by high shear homogenisation followed by ultrasonication method.

was determined by Malvern Zetasizer and the average values of triplicates were taken. ${ }^{14}$

\section{Drug Content}

NLCs loaded with $1 \mathrm{mg}$ equivalent amount of Felodipine was added to $10 \mathrm{ml}$ of methanol: phosphate buffer $\mathrm{pH} 6.8$ (1:10) with continuous stirring for $2 \mathrm{hr}$. Obtained colloidal suspension was subjected to ultracentrifugation at $10,000 \mathrm{rpm}$ for $30 \mathrm{~min}$. Then, supernatant was collected, suitably diluted and further analyzed for drug content spectrophotometrically at $363 \mathrm{~nm} .{ }^{15}$

\section{Entrapment Efficiency}

The entrapment efficiency of NLCs was determined by ultracentrifugation method. The obtained supernatant after ultracentrifugation of NLCs $(30,000 \mathrm{rpm}$ at $25^{\circ} \mathrm{C}$ ) for $30 \mathrm{~min}$ was suitably diluted with $\mathrm{pH} 6.8$ phosphate buffer and analysed for unassociated drug spectrophotometrically at $363 \mathrm{~nm} .{ }^{16}$ The Felodipine encapsulation efficiency of the nanoparticles was calculated as follows:

$$
\% \text { Efficiency }=\frac{\begin{array}{l}
\text { Total amount of drug }- \\
\text { Total amount of unbounded drug }
\end{array}}{\text { Total amount of drug }} \times 100
$$

\section{Transmission Electron Microscopy (TEM)}

External morphology of prepared nanosuspension was determined by using transmission electron microscopy. Samples of the nanosuspension were prepared by placing a drop onto copper grid. Digital Micrograph and Soft Imaging Viewer software were used to perform the image capture and analysis, including particle sizing.

\section{In vitro Drug Release}

Suspension of NLCs equivalent to $10 \mathrm{mg}$ of Felodipine was transferred to a dialysis bag (mol. weight cut off 12,000-14,000 Dalton) and sealed. The bag was then immersed for $2 \mathrm{hrs}$ in dissolution apparatus containing $900 \mathrm{ml}$ of $0.1 \mathrm{~N} \mathrm{HCl} \mathrm{pH} 1.2$ buffer followed by $\mathrm{pH}$ 6.8 phosphate buffer for about $12 \mathrm{hr}$ with a constant speed of $50 \mathrm{rpm}$ at $37^{\circ} \mathrm{C} \pm 0.5^{\circ} \mathrm{C}$. Required quantities of test samples were withdrawn at regular intervals and the same quantities were replaced with fresh solution of buffers. The samples were suitably diluted and analyzed spectrophotometrically at $363 \mathrm{~nm} \cdot{ }^{17,18}$

\section{Kinetics of Drug Release}

To study the release mechanism and release rate kinetics of NLCs, the obtained data was fitted in to Zero order, First order, Higuchi matrix, Hixson Crowell and Korsmeyer- Peppas model. On the basis of $R^{2}$ values obtained, the best fit model was chosen by using Microsoft excel Windows version 7.

\section{In vivo Bioavailability Studies}

Ethical approval was received from the Institutional Animal Ethics Committee prior to the beginning of research work. The animals were procured from in vivo Biosciences, Bengaluru by Institutional Animal Ethics Committee and provided for the study. Healthy male Wistar rats weighing $150-200 \mathrm{gms}$ were housed in polypropylenecages and maintained at room temperature under $12 \mathrm{~h}$ dark/light cycles. They were fed with standard pelleted diet and water. The animals were acclimatized for one week under laboratory conditions before experiments on the animals. The animals were fasted overnight and had free access to water throughout the experimental period. Twelve healthy male wistar rats were selected and divided into 2 groups each group 
containing 6 rats. Group 1 received marketed product of Felodipine $0.108 \mathrm{mg}$ in normal saline by oral route. Group 2 received NLCs containing equivalent to $0.108 \mathrm{mg}$ of Felodipine for 6 animals in normal saline through oral route. After $0.5,2,4,6,8,10,12$ and $24 \mathrm{hr}$, $0.5 \mathrm{ml}$ of blood was collected from eye by retro-orbital puncture into eppendorf tube with $10 \mu \mathrm{l}$ of EDTA. The samples were centrifuged at $5000 \mathrm{rpm}$ for $20 \mathrm{~min}$. Supernatant plasma was taken and filtered through $0.45 \mu \mathrm{m}$ membrane into clean vials and then analyzed in UV Spectrophotometry. ${ }^{19}$

\section{Short Term Stability Studies}

The stability studies were conducted according to $\mathrm{ICH}$ guidelines. Samples were stored in glass vials for 60 days at $4^{\circ} \mathrm{C}$ and at room temperature $\left(25 \pm 2^{\circ} \mathrm{C}\right)$. After 30, 60 and 90 days samples were evaluated for $\%$ entrapment efficiency and in vitro drug release studies. ${ }^{20}$

\section{Statistics}

The data as described in the experimental sections was statistically analysed by performing two-way analysis of variance (ANOVA) using GraphPad Prism 7.0 software; a value of $P<0.05$ were found to be statistically significant in all the cases.

\section{RESULTS}

\section{Preliminary Lipid Screening}

For solid lipid, Felodipine has shown maximum solubility in Compritol ATO 888 and solubility was in an order of Compritol ATO 888>stearic acid > Glyceryl monostearate. For liquid lipid Felodipine has shown maximum solubility in oleic acid and solubility was in an order of Oleic acid> Ethyl Oleate> Olive oil.

\section{Optimization of Process Parameters}

Optimization of process parameters was done by varying homogenization speed, homogenization time, ultrasonication time and surfactant concentration as shown in Table 1. Based on desired particle size, PDI and reproducible results the optimized parameters selected were as follows; homogenization speed-1400rpm, homogenization time-30 min, ultrasonication time -15 min and surfactant concentration $-1.0 \%$. The results are shown in Table 2.

\section{Evaluation of Felodipine NLCs Formulations}

\section{Particle size and size distribution}

The mean particle size for formulation F1 to F5 varied in the range of $187.0 \pm 0.06 \mathrm{~nm}$ to $321.9 \pm 0.01 \mathrm{~nm}$. The NLCs mean particle size was found to be reduced with increasing the concentration of lipid up to certain range. Further increase in lipid concentration showed an increase in the mean particle size of NLCs. The mean Polydispersity index of NLCs loaded with drug (F1 to F5) varied between the ranges of $0.259 \pm 0.002$ to $0.382 \pm 0.004$ as tabulated in Table 3 .

\section{Zeta Potential}

It has been reported that the value of zeta potential less than $-30 \mathrm{mV}$ or higher than $+30 \mathrm{mV}$ predicts good physical stability of nanoparticles dispersion. Zeta potential of F1-F5 are given in Table 3 which are in the range of -22.9 to $38.2 \mathrm{mV}$ and Figure 2 shows the zeta potential of $\mathrm{F} 2$ formulation.

\section{Drug Content and Entrapment Efficiency}

The percent drug content and encapsulation efficiency for formulations F1 to F5 were ranged between 51.15\% to $69.13 \%$ and $53.33 \%$ to $80.15 \%$ respectively (Table 3 ).

\section{SEM and TEM Analysis}

SEM and TEM images of optimized NLCs formulation F2 indicated that, the prepared NLCs were in nano size range. SEM and TEM images of the optimized NLCs formulation F2 is shown in the Figure $3 \mathrm{~A}$ and Figure $3 \mathrm{~B}$ respectively.

\section{In vitro Drug Release}

The drug release at the end of $2 \mathrm{~h}$ for F1-F5 was found to be in the range of $17.69 \%-20.01 \%$, this release is due to the drug present on the surface of nanoparticles. At the end of $12 \mathrm{~h}$ the mean cumulative release of drug from

\begin{tabular}{|c|c|c|c|c|c|}
\hline \multicolumn{6}{|c|}{ Table 3: Particle Size and Polydispersity Index, \%Drug Content, \% Entrapment Efficiency and Zeta Potential. } \\
\hline Formulation & Particle size* & PDI $^{*}$ & $\begin{array}{c}\text { Percent Drug } \\
\text { content }^{*}\end{array}$ & $\begin{array}{c}\text { Percent Entrapment } \\
\text { efficiency }^{*}\end{array}$ & Zeta potential (mV) $^{\text {(m) }}$ \\
\hline F1 & $203.0 \pm 0.06$ & $0.282 \pm 0.032$ & $51.15 \pm 001$ & $53.33 \pm 0.004$ & -24.1 \\
\hline F2 & $187.0 \pm 0.01$ & $0.259 \pm 0.002$ & $69.14 \pm 003$ & $80.15 \pm 0.003$ & -38.2 \\
\hline F3 & $192.3 \pm 0.004$ & $0.274 \pm 0.005$ & $66.12 \pm 002$ & $74.0 \pm 0.005$ & -22.9 \\
\hline F4 & $253.5 \pm 0.02$ & $0.349 \pm 0.003$ & $55.24 \pm 007$ & $62.27 \pm 0.003$ & -22.5 \\
\hline F5 & $321.9 \pm 0.01$ & $0.382 \pm 0.004$ & $54.13 \pm 004$ & $58.33 \pm 0.006$ & -24.0 \\
\hline
\end{tabular}

${ }^{*}$ Results are expressed as mean \pm standard deviation (mean \pm SD) $n=3$ 


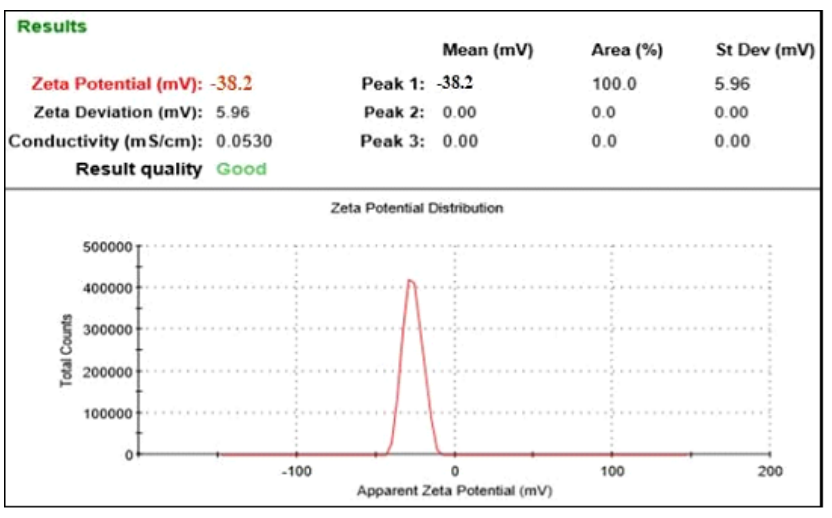

Figure 2: Zeta potential of formulation F2.

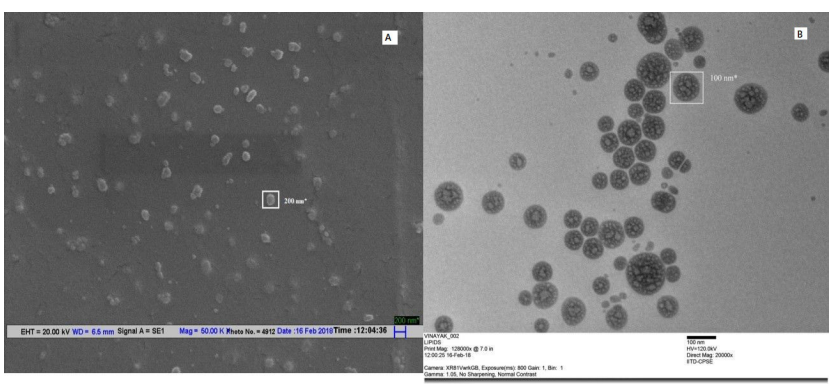

Figure 3: A) Scanning Electron Microscopy B) Transmission Electron Microscopy of optimized formulation F2.

F1-F5 was found to be in the range of $50.60-72.82 \%$. The in-vitro release profiles of formulations F1-F5 are shown in Figure 4 and the release profile of optimized F2 formulation and pure drug is compared in Figure 5. All formulations F1 to F5 showed biphasic drug release profile, with beginning burst release of drug which was due to surface drug adsorption, this phase is followed by a phase of slower drug release. In the second phase, the mechanism of drug release is diffusion of entrapped drug from inside the NLCs in to the release medium. Pure drug release profile showed $\sim 50 \%$ drug release in $12 \mathrm{hrs}$, whereas the optimized NLCs formulation F2 showed drug release of about $72.82 \%$ up to $12 \mathrm{hrs}$ which indicates increase in bioavailability of nano formulation (shown in Figure 4).

\section{In-vitro Kinetics of Drug Release}

The release data obtained was fitted in to different kinetic models to determine the release constant as well as regression coefficient $\left(\mathrm{R}^{2}\right)$. Based on the obtained regression coefficients, the drug release profile of NLCs formulations (F1-F5) were best fitted with Higuchi Matrix model.

\section{In vivo Studies}

The study was carried out on male Wistar rats for the comparison of plasma drug concentration of

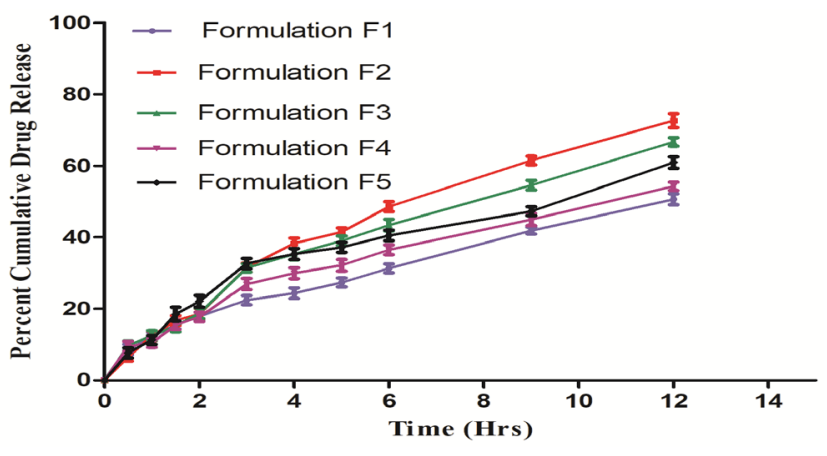

Figure 4: In vitro dissolution profile of the formulations F1 to F5.

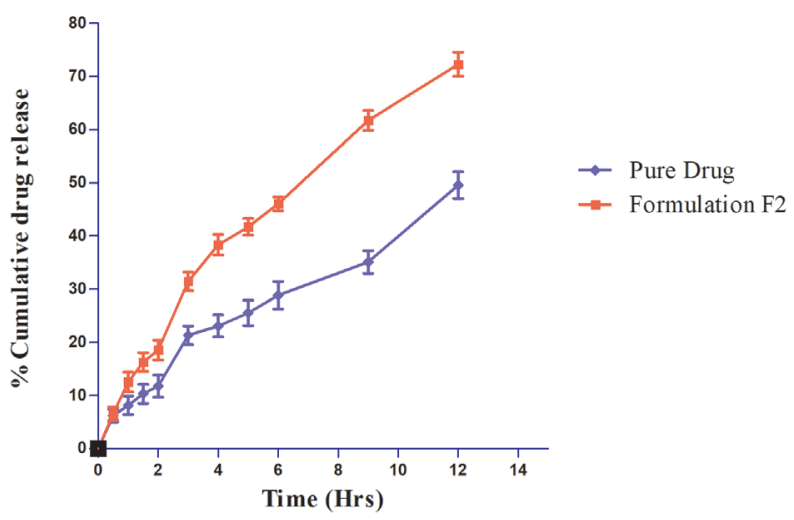

Figure 5: Comparative in vitro drug release profile of optimized formulation F2 and pure drug.

optimized NLCs formulation F2 with the marketed product which were given orally with normal saline. Comparative graph of plasma concentration $v / s$ time of optimized formulation F2 and marketed product was plotted (Figure 6). AUC of Marketed product was found to be $81.1 \mu \mathrm{g} / \mathrm{ml}$. h, $\mathrm{C}_{\max }$ of $4.569 \mu \mathrm{g} / \mathrm{ml}$ and $\mathrm{T}_{\max }$ of $4 \mathrm{~h}$ when given orally, whereas optimized formulation F2 showed AUC of $222.7 \mu \mathrm{g} / \mathrm{ml} . \mathrm{h}, \mathrm{C}_{\max }$ of $13.040 \mu \mathrm{g} / \mathrm{ml}$ and $\mathrm{T}_{\max }$ of $8 \mathrm{~h}$, which was calculated by Trapezoidal method. AUC ${ }_{0-t}$ of Marketed product $81.1 \mu \mathrm{g} / \mathrm{ml}$. h was increased up to $222.7 \mu \mathrm{g} / \mathrm{ml}$. h for optimized formulation $\mathrm{F} 2$ when given through oral route.

\section{Statistical Correlation}

For the statistical correlation of in-vivo bioavailability, the number of animals in each group $(n)=6$ were taken. Two-way ANOVA was applied for the statistical comparison of data. Degree of freedom was taken $5 \%$. ${ }^{*} p<0.05$ and $* * * p<0.001$ compared to marketed formulation. If the hypothesis is $95 \%$ of confidence then degree of freedom is $5 \%(p \leq 0.05)$. If the hypothesis is $99 \%$ of confidence then the degree of freedom $1 \%$ 


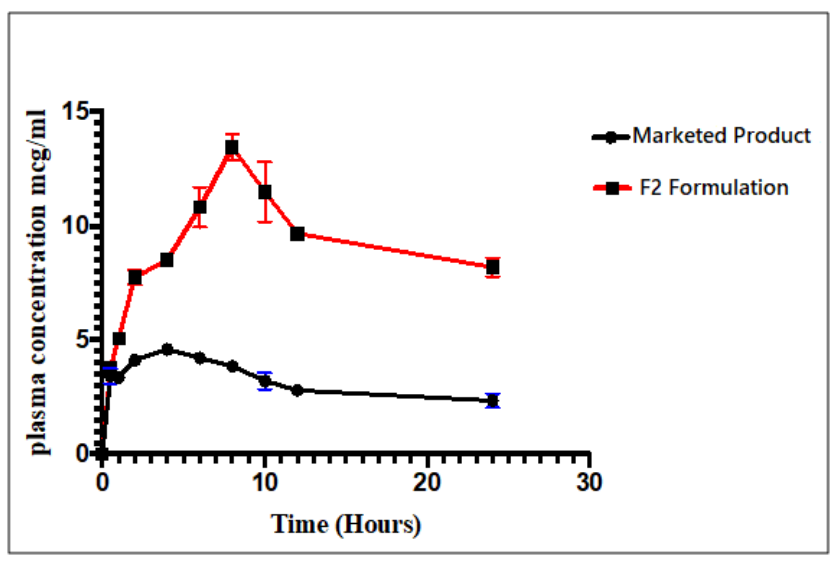

Figure 6: Comparative in-vivo release profile of Optimized formulation F2 and marketed product by oral administration.

$(p \leq 0.01)$. Here null hypothesis is not working so that alternative hypothesis comes into existence.

\section{Short Term Stability Studies}

The results of stability studies show no significant difference with respect to entrapment efficiency and cumulative percentage drug release of F2 formulation stored at $4 \pm 2^{\circ} \mathrm{C} / 65 \pm 5 \% \mathrm{RH}$ compared to that stored at room temperature. Thus, formulation stored at $4 \pm 2^{\circ} \mathrm{C} / 65 \pm 5 \% \mathrm{RH}$ showed better stability as compared to the formulation stored at $25 \pm 2^{\circ} \mathrm{C} / 65 \pm 5 \% \mathrm{RH}$.

\section{DISCUSSION}

A new form of NLCs comprising of lipid matrix and having a unique nanostructure have been developed. These carriers enhance drug loading as well as incorporate drug firmly during its storage. Solid-lipid nanoparticles (SLN) can be exploited as efficient delivery systems in commercial production but these show certain limitations like, higher water content in the nanolipid and possibility of drug expulsion during storage. ${ }^{21}$ Mainly to avoid drug expulsion, combination of lipids that does not form highly ordered crystalline arrangements is required. Thus, NLCs come in to existence as they consist of combination of solid and liquid lipids, which results in matrix with higher imperfections to accommodate higher drug molecule than SLN.

Around $40 \%$ of the APIs face solubility problems which lead to their low oral bioavailability. Felodipine, an antihypertensive drug that belongs to BCS Class II i.e. low solubility and high permeability and have oral bioavailability of only $15 \%$. In order to overcome this problem, Felodipine loaded nanostructured lipid carrier was formulated so as to reduce the particle size of the drug, thereby increasing the dissolution rate and hence the oral bioavailability. It was also aimed to provide sustained manner of drug release for prolonged period of time, thus reducing the dosing frequency.

Preliminary lipid screening was performed with different solid and liquid lipids to select a suitable lipids in the formulation of NLCs. Felodipine has shown maximum solubility in Compritol ATO 888 and Oleic acid, this might be due to structural convenience between Compritol ATO 888, Oleic acid and Felodipine. On the basis of Lipid screening Compritol ATO 888 and Oleic acid were selected for formulation of NLCs. Also, for better and reproduceable results, process parameters such as homogenization speed, homogenization time, and ultrasonication time and surfactant concentration were optimized in the preliminary study.

A total five formulations (F1-F5) were formulated by using solid lipid Compritol ATO 888, liquid lipid oleic acid and a surfactant poloxamer 188 with the use of high shear homogenization followed by ultrasonication method and evaluated. Among all formulations of NLCs, F2 formulation with drug: lipid ratio of 1:1.5 shows lower particle size (nano range) of $187.0 \pm 0.06 \mathrm{~nm}$. Polydispersity index suggests the width of particle size distribution that ranges between 0 to 1 . If a PDI value is neared to 0 indicates the monodispersion of sample. However, PDI $<0.2$ is considered as narrow size distribution whereas a PDI $>0.5$ indicates a very broad distribution. Therefore, PDI measurement was essential to confirm the size distribution of the particles and F2 NLCs formulation showed lower PDI indicating homodispersion. Zeta potential is used to demonstrate the charge stability of dispersed systems. Zeta potential of NLCs F2 was found to be $-38.2 \mathrm{mV}$ which indicates good stability of formulation. This is due to surfactant that reduces the electrostatic repulsion among the particles and sterically stabilizes the particles by forming a coat around their surface. Formulation F2 demonstrated maximum drug content as well as entrapment efficiency of $69.14 \pm 003 \%$ and $80.15 \pm$ $0.003 \%$ respectively. Also, formulation F2 which has a lowest mean particle size has resulted in maximum percent release of drug $(72.82 \%)$ at the end of $12 \mathrm{~h}$. This is because, smaller the particle size greater will be the surface area compared to their volume, thus, almost all drug will be at or near the particle surface which can be easily released. In contrary, larger particles possess large cores which leads to more drug encapsulation but slowly diffuses out. Based on these all findings of NLCs evaluation, F2 formulation can be considered as optimized formulation. 
Encapsulation efficiency and drug content were enhanced with increasing concentration of solid lipid (up to $15 \mathrm{mg}$ ), further increase in concentration of solidlipid(upto $30 \mathrm{mg}$ )leads todecreasein theentrapment efficiency. This is because, in NLCs molecules of lipid (solid and liquid) distributed in lipid matrix and an imperfect structured nanoparticle were formed, that enhances drug entrapment in structure. At higher contents of lipids, increasing drug to lipid ratio reduces entrapment efficiency due to reduced drug- lipid miscibility. ${ }^{22,23}$

The in vivo study was performed on male Wistar rats and plasma drug concentration of optimized F2 formulation of NLCs was compared with that of marketed product plasma drug concentration. As the AUC $_{0-\mathrm{t}}$ obtained for marketed product was $81.1 \mu \mathrm{g} / \mathrm{ml}$. $\mathrm{h}$ and that of optimized formulation F2 was $222.7 \mu \mathrm{g} /$ $\mathrm{ml}$. h (calculated by Trapezoidal method), the NLCs of Felodipine were capable of enhancing the bioavailability by 2.0 folds when compared to the bioavailability of marketed product and efficiently sustain the release of drug for prolonged time period. Thus, from the present study it can be concluded that NLCs prepared with proper process and formulation optimization could significantly enhance the bioavailability of poorly water-soluble drug Felodipine.

\section{CONCLUSION}

Five formulations of Felodipine loaded Nanostructured lipid carriers were successfully prepared with high shear homogenization and ultrasonication method. Based on evaluation results of NLCs, F2 formulation was considered as optimized formulation for further evaluation. SEM and TEM images suggested that the particle size of F2 formulation were in nano range. Zeta potential was found to be between -22.5 to -38.2 which predict good physical stability of nanoparticles dispersion. The dissolution rate depends upon the mean particle size. Therefore, F2 formulation showed maximum release i.e. $72.82 \pm 0.002 \%$. For in vivo bioavailability study male Wistar rats were subjected to the pharmacokinetic study. Stability studies carried out for optimized formulation F2 showed that the NLCs were more stable at $4 \pm 2^{\circ} \mathrm{C}$. In conclusion, Nanostructured lipid carriers loaded with Felodipine were capable of enhancing the bioavailability of drug by 2.0 folds in comparison to marketed product and also demonstrated sustained drug release pattern for longer period of time.

\section{Ethical approval}

Ethical approval was obtained from Institutional Animal Ethics Committee prior to the beginning of research work. (Resolution No: KLECOP/CPCSEA/ Re.no.221/PO/RE/S/2000/CPCSEARes.25-09/09/2017). In this study, all the procedures using Wistar rats, weighed 150-200 g, male, 6-8 weeks of age, were provided by the Institutional Animal Ethics Committee of KLE College of Pharmacy, Belagavi, Karnataka, India and was performed out in accordance with the guidelines provided by the Committee for the Purpose of Control and Supervision of Experiments on Animals (CPCSEA), Government of India.

\section{ACKNOWLEDGEMENT}

Authors are thankful to their regards to Dr. Prabhakar Kore Basic Science Research Centre, KLE Academy of Higher Education and Research Belagavi, for providing their amenities to carry out this work. The authors are also thankful to Cipla Pvt. Ltd. Bangalore, India, for providing Felodipine pure drug as gift sample. The authors are thankful to Kesar Control System, AICTEMODROB 2017-2018 for providing stability chamber to carry out the stability studies in research work. Authors are also thankful AICTE-MODROBE for providing Ultrasonic probe sonicator VC750.

\section{CONFLICT OF INTEREST}

The authors declare that they have no any conflict of interests.

\section{ABBREVIATIONS}

BCS: Biopharmaceutical Classification System; NLCs: Nanostructured lipid carriers; TEM: Transmission Electron Microscope; SEM: Scanning Electron Microscope; SD: solid dispersions; SMEDDS: Self Micro Emulsifying Drug Delivery System; PDI: Polydispersity Index; AUC: Area Under Curve.

\section{REFERENCES}

1. Bolívar JJ. Essential hypertension: an approach to its etiology and neurogenic pathophysiology. Int J Hypertens. 2013;2013:547809. doi: 10.1155/2013/547809. PMID 24386559.

2. Jana U, Mohanty AK, Pal SL, Manna PK, Mohanta GP. Felodipine loaded PLGA nanoparticles: preparation, physicochemical characterization and in vivo toxicity study. Nano Converge. 2014;1(1):1-10.

3. Felodipine [internet] [[updated on May 20, 2018], created on June 13, 2005]. Available from: https://www.drugbank.ca/drugs/DB01023.

4. Won DH, Kim MS, Lee S, Park JS, Hwang SJ. Improved physicochemical characteristics of felodipine solid dispersion particles by supercritical anti- 
solvent precipitation process. Int J Pharm. 2005;301(1-2):199-208. doi: 10.1016/j.jpharm.2005.05.017, PMID 16024189.

5. Luo C, Li Y, Sun J, Zhang Y, Chen Q, Liu X, He Z. Felodipine nanosuspension: a faster in vitro dissolution rate and higher oral absorption efficiency. J Drug Deliv Sci Technol. 2014;24(2):173-7. doi: 10.1016/S1773-2247(14)50028-7.

6. Sahu BP, Das MK. Nanosuspension for enhancement of oral bioavailability of felodipine. Appl Nanosci. 2014;4(2):189-97. doi: 10.1007/s13204-012-0188-3.

7. Grandhi S, Prameelarani A, Swathi A, Manasa B. Development of extended release matrix tablets of felodipine through solid dispersions for better drug release profile by a $3^{2}$ factorial design. Indian J Pharm Educ. 2016;50(2):89-95.

8. Anusha A, Krishnaveni J. Development of felodipine loaded SMEDDS for improving oral bioavailability. Int J Pharm Sci Res. 2018;9(10):4286-93.

9. Uprit S, Kumar Sahu RK, Roy A, Pare A. Preparation and characterization of minoxidil loaded nanostructured lipid carrier gel for effective treatment of alopecia. Saudi Pharm J. 2013;21(4):379-85. doi: 10.1016/j.jsps.2012.11.005, PMID 24227958.

10. Khan S, Baboota S, Ali J, Khan S, Narang RS, Narang JK. Nanostructured lipid carriers: an emerging platform for improving oral bioavailability of lipophilic drugs. Int J Pharm Investig. 2015;5(4):182-91. doi: 10.4103/2230973X.167661, PMID 26682188.

11. Poonia N, Kharb R, Lather V, Pandita D. Nanostructured lipid carriers: versatile oral delivery vehicle. Future Sci OA. 2016;2(3):FSO135. doi: 10.4155/fsoa-2016-0030, PMID 28031979.

12. Li Q, Cai T, Huang Y, Xia X, Cole SPC, Cai Y. A Review of the Structure, Preparation, and Application of NLCs, PNPs, and PLNs. Nanomaterials (Basel). 2017;7(6):122. doi: 10.3390/nano7060122, PMID 28554993.

13. Teeranachaideekul $\mathrm{V}$, Müller RH, Junyaprasert VB. Encapsulation of ascorbyl palmitate in nanostructured lipid carriers (NLC)--effects of formulation parameters on physicochemical stability. Int J Pharm. 2007;340(1-2):198206. doi: 10.1016/j.ijpharm.2007.03.022, PMID 17482778.

14. Chen CC, Tsai TH, Huang ZR, Fang JY. Effects of lipophilic emulsifiers on the oral administration of lovastatin from nanostructured lipid carriers: physicochemical characterization and pharmacokinetics. Eur J Pharm Biopharm. 2010;74(3):474-82. doi: 10.1016/j.ejpb.2009.12.008, PMID 20060469.
15. Zhang T, Chen J, Zhang Y, Shen Q, Pan W. Characterization and evaluation of nanostructured lipid carrier as a vehicle for oral delivery of etoposide. Eur J Pharm Sci. 2011;43(3):174-9. doi: 10.1016/j.ejps.2011.04.005, PMID 21530654.

16. Cy Z, Li N, Wang M, Zhang XN, Pan SW, Peng JJ, Pan YS, Tang X. Preparation and characterization of vinpocetine loaded nanostructured lipid carriers (NLC) for improved oral bioavailability. Int J Pharm. 2011;394(1-2): 179-85.

17. Emami J, Rezazadeh M, Varshosaz J, Tabbakhian M, Aslani A. Formulation of LDL Targeted Nanostructured Lipid Carriers Loaded with Paclitaxel: A Detailed Study of Preparation, Freeze Drying Condition, and In Vitro Cytotoxicity. J Nanomater. 2012;2012:1-10. doi: 10.1155/2012/358782.

18. Soleimanian Y, Goli SAH, varshosaz J, Sahafi SM. Formulation and characterization of novel nanostructured lipid carriers made from beeswax, propolis wax and pomegranate seed oil. Food Chem. 2018;244:83-92. doi: 10.1016/j.foodchem.2017.10.010, PMID 29120809.

19. Ustündağ-Okur N, Gokçe EH, Bozbıyık Di, Eğrilmez S, Ozer O, Ertan G. Preparation and in vitro-in vivo evaluation of ofloxacin loaded ophthalmic Nano structured lipid carriers modified with chitosan oligosaccharide lactate for the treatment of bacterial keratitis. Eur J Pharm Sci. 2014;63:204-15. doi: 10.1016/j.ejps.2014.07.013, PMID 25111119.

20. $\mathrm{ICH}$. Topic $\mathrm{Q} 1 \mathrm{~A}(\mathrm{R} 2)$ stability testing of new drug substances and products. European Medicines Agency. CPMP/ICH/2736/99; August 2003.

21. Salvi VR, Pawar P. Nanostructured lipid carriers (NLC) system: A novel drug targeting carrier. J Drug Deliv Sci Technol. 2019;51:255-67. doi: 10.1016/j. jddst.2019.02.017.

22. Noori Siahdasht FN, Farhadian N, Karimi M, Hafizi L. Enhanced delivery of melatonin loaded nanostructured lipid carriers during in vitro fertilization: NLC formulation, optimization and IVF efficacy. RSC Adv. 2020;10(16):9462-75. doi: 10.1039/C9RA10867J.

23. Kiss LE, Berko S, Gacsi A, Kovacs A, Katona G, Soos J, Csányi E, Grof I, Harazin A, Deli MA, Budai-Szucs M. Design and optimization of nanostructured lipid carrier containing dexamethasone for ophthalmic use. Pharmaceutics. 2019;11(12):1-18.

\section{SUMMARY}

- Nanostructured lipid carriers of Felodipine were successfully prepared by using high shear homogenization and ultrasonication teqniques.

- Preformulation study to determine drug-excipient compatibility was carried out by FTIR and DSC, which revealed that, the drug sample was pure and the lipids and surfactant used were compatible with Felodipine.

- A total five formulations (F1-F5) were prepared by using Compritol ATO 888 as solid lipid, oleic acid as liquid lipid and poloxamer 188 as a surfactant.

- Felodipine loaded NLCs were characterised for their particle size, polydispersity index, $\%$ drug content, $\%$ entrapment efficiency, zeta potential, surface morphology, in-vitro drug release studies, in-vivo bioavailability and stability studies.

- Based on evaluation results of NLCs, F2 formulation was considered as optimized formulation for further evaluation.

- Zeta potential of optimized formulation F2 was -38.2 showed good stability.

- In vitro drug release study showed initial burst effect, this may be due to drug present on the surface of NLC followed by sustained release.

- Developed UV method was used for determination of Felodipine in rat plasma for bioavailability and pharmacokinetic evaluation.

- The relative bioavailability of NLC formulation showed an enhanced bioavailability of 2.0 times greater than that of Marketed product. 


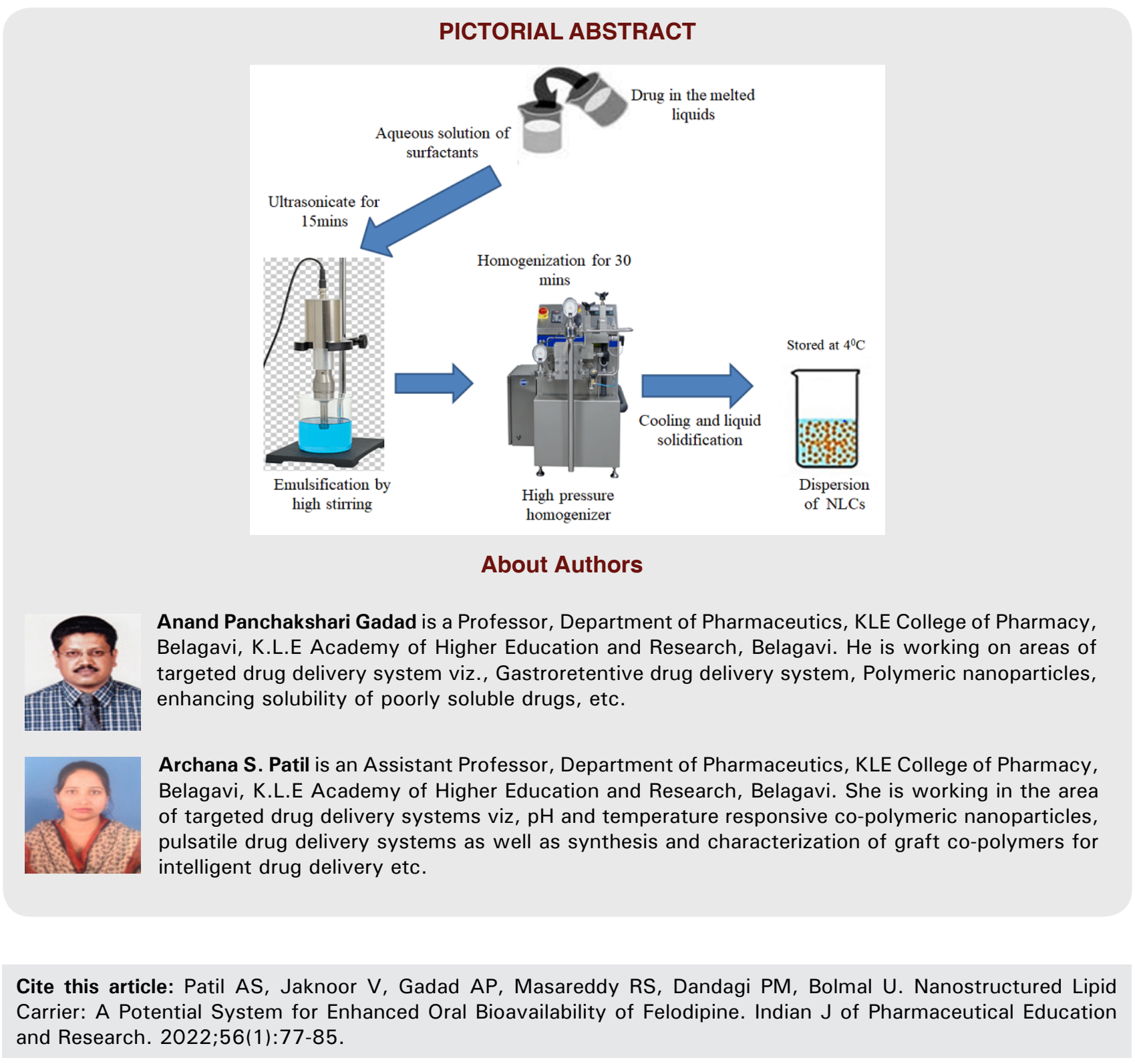

